\title{
A Practical Approach to Density Management
}

\author{
by
}

\author{
James N. Long'
}

\begin{abstract}
Density management is the control of growing stock, through initial spacing or subsequent thinning, to achieve specific management objectives. A biologically sound and easily applied approach to density management is illustrated for a hypothetical, even-aged stand under two contrasting types of management objectives.
\end{abstract}

\section{Résumé}

L'aménagement par densité est le contrôle du volume sur pied grâce à l'esplacement initial et aux éclaircies subséquentes pour atteindre des objectifs d'aménagement spécifiques. Une approche biologiquement solide et facilement applicable de l'aménagement par densité est illustrée pour un peuplement équienne hypothétique selon deux différents types d'objectifs d'aménagement.

\section{Introduction}

Density management is the manipulation and control of growing stock to achieve specific management objectives. While the actual control of growing stock is relatively easy to achieve through initial spacing and intermediate cuttings, the determination of appropriate levels of growing stock at the stand level is a complex process involving biological, technological and economic factors specific to a particular management situation (Davis 1966). The objective of this paper is to review and illustrate a basic approach to density management that is biologically sound, easily applied, and flexible in facilitating a wide range of management objectives.

\section{Size-density Relationships as Indices of Growing Stock}

The most generally effective indices of growing stock are those that combine some expression of mean size (e.g. mean weight, volume, height or $\mathrm{DBH}$ ) and density (e.g. trees/ha) (Curtis 1970, 1971; Long and Smith 1984). Perhaps the most familiar of these indices is Reineke's (1933) stand density index (SDI), based on the predictable relationship between quadratic mean diameter and trees per unit area in dense stands. SDI represents one of a number of basic size-density relationships. Others that have been suggested as measures of growing stock include mean volume-density (Drew and Flewelling 1977) and mean height-density (Wilson 1979). Many other stand density indices are variations based on one of these basic size-density relations (Curtis 1971).

'College of Natural Resources, Utah State University, Logan, Utah 84322. USA Utah State University Agricultural Experiment Station Journal Paper No. 2939.
The relation between average size and density of individuals in populations experiencing density-related or suppression mortality has been shown to be exceedingly predictable (Figure 1) for a number of herbaceous and tree species (Gorham 1979: White 1980). In the ecological literature, the relation is commonly referred to as the "self-thinning rule" (Yoda et al. 1963). This fundamental relationship, independent of both stand age and site quality, provides an excellent basis from which to develop an understanding of the competitive interactions between individuals in a population (Hutchings and Budd 1981; Long and Smith 1984). The self-thinning rule is the basis of various stand density indices, including SDI, and its practical application in the analysis and management of stand density has been demonstrated for a number of species (Ando 1968; Drew and Flewelling 1979; McCarter 1984).

Much of the value and potential application of these sizedensity indices in density management result from the fact that they are independent of site quality and stand age. They therefore confer the ability to compare levels of growing stock (and thus competitive stress, degree of site occupancy and growth as a percent of potential) regardless of differences in site quality or stand age. A stand density that is deemed ideal in the context of a particular set of management objectives can be projected forward or backward to a different stage of stand development. Growth-growing stock relations (for example, those based on stocking control studies) can be translated into density management prescriptions for stands of different ages and site quality.

An advantage of Reineke's SDI is the ease with which it can be estimated and applied. The SDI for a stand is the number of trees per ha (tpha) as if the quadratic mean diameter $\left(\mathrm{DBH}_{\mathrm{q}}\right)$ 
(trees/ho)

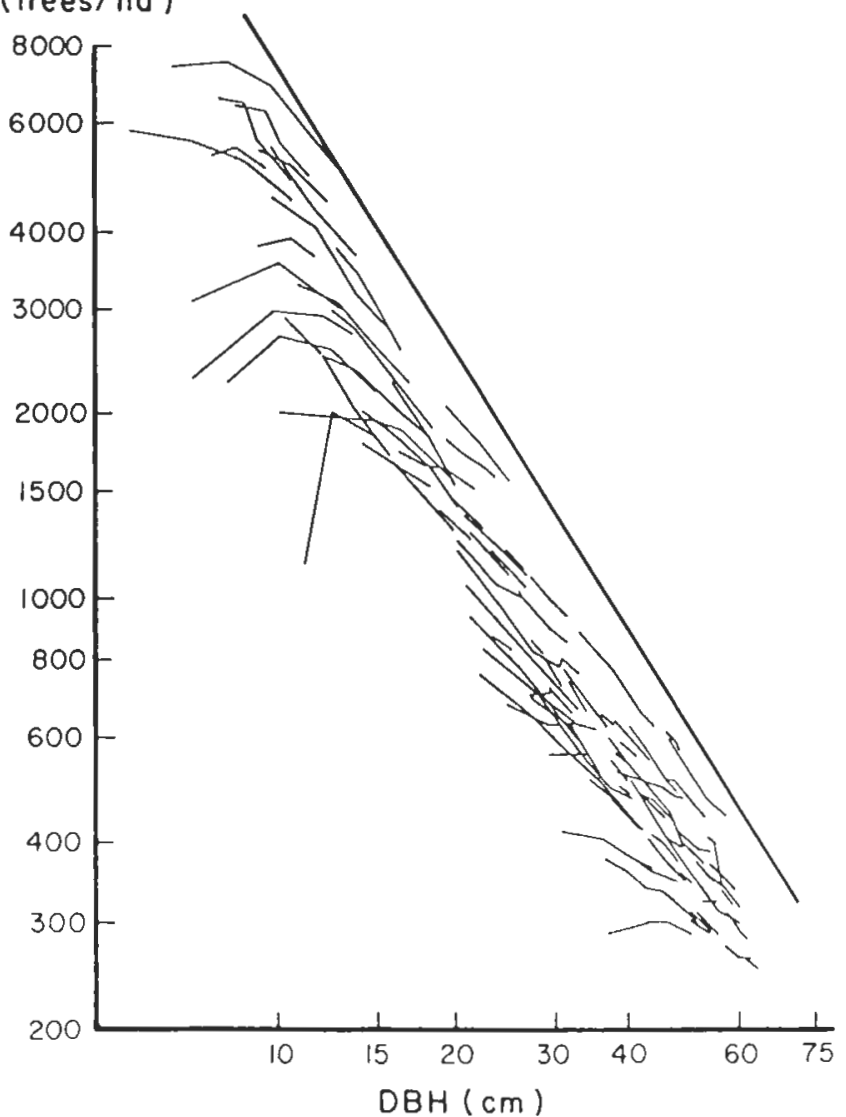

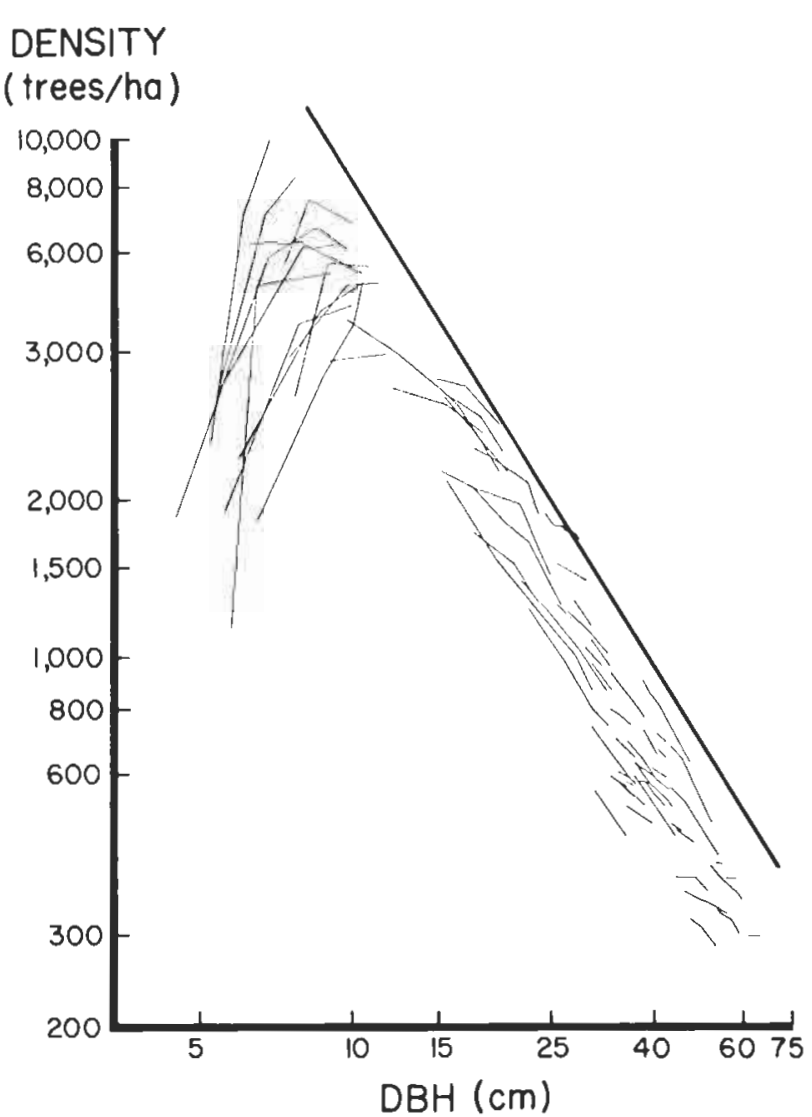

Figure 1. Relation between mean DBH and density for self-thinning stands of Douglas-fir (A) and western hemlock (B). (after Wiley 1976).

were $25 \mathrm{~cm}$. Given the actual tpha and $\mathrm{DBH}_{\mathrm{q}}$. SDI can be calculated (Daniel and Sterba 1980) with the formula:

$$
\begin{aligned}
& \text { (1) } \mathrm{SDI}=\text { tpha }\left(\mathrm{DBH}_{\mathrm{q}} / 25\right)^{16} \\
& \text { where: } \text { ipha }=\text { observed trees } / \text { ha } \\
& \mathrm{DBH}_{\mathrm{q}}=\text { diameter of tree of average }
\end{aligned}
$$

Given any two of the stand parameters, it is possible to solve for the third following simple algebraic manipulation:
(2) tpha $=\mathrm{SDI} /\left(\mathrm{DBH}_{\mathrm{q}} / 25\right)^{1.6}$
(3) $\mathrm{DBH}_{\mathrm{q}}=25$ (SDI/tpha) $)^{0.625}$

While the calculation of SDI is independent of species, the significance of a particular SDI varies from one species to another (Table 1). For the sake of generality in this discussion, I shall refer to SDI as percent of the maximum for the species.

\section{Designing a Density Management Regime}

In the approach to density management advocated here, management objectives are translated into specific target levels of growing stock. In principle, the stand is allowed to grow to the targeted upper limit of growing stock and is thinned down to the lower limit. This process is repeated as many times as necessary. Typically some modification of this simple process is needed to accommodate some aspect of the management objectives, such as mimimum merchantable tree size and minimum volume removal per entry.

The translation of specific management objectives into appropriate upper and lower levels of growing stock is, of course, the key to and most difficult step in designing a density management regime (Davis 1966). The use, however, of a size-density based index of growing stock, such as SDI,

\begin{tabular}{|c|c|c|c|c|c|}
\hline \multicolumn{6}{|c|}{ Species } \\
\hline & $\begin{array}{c}\% \text { of } \\
\max . \text { SDI }\end{array}$ & $\begin{array}{l}\text { Ponderosa } \\
\text { pine }\end{array}$ & $\begin{array}{l}\text { Lodgepole } \\
\text { pine }\end{array}$ & $\begin{array}{l}\text { Douglas- } \\
\mathrm{fir}\end{array}$ & $\begin{array}{l}\text { Western } \\
\text { hemlock }\end{array}$ \\
\hline Maximum & 100 & 2050 & 1700 & 1450 & 1950 \\
\hline Lower limit of "full site occupancy" & 35 & 720 & 600 & 510 & 680 \\
\hline On-set of competition' & 25 & 510 & 425 & 360 & 490 \\
\hline
\end{tabular}
greatly simplifies the process.

Table 1. Examples of "key" SDI values for various species.

'This roughly corresponds to "initial crown closure". see Drew and Flewelling (1977) for

discussion. 
Density management regimes, and the upper and lower limits to growing stock, typically represent a compromise between maximization of volume production on an area basis (e.g. $\mathrm{m}^{3} / \mathrm{ha} / \mathrm{yr}$ ) and maximization of individual tree growth and size. This is because both aspects of growth (i.e. stand versus individual) cannot be simultaneously maximized. Figure 2 illustrates the general relation between current annual growth and level of growing stock, represented by SDI as a percent of the species maximum SDI. For stands undergoing selfthinning, net growth of the stand will of course decline; gross stand growth will, barring stagnation, remain on the "plateau" of the curve.
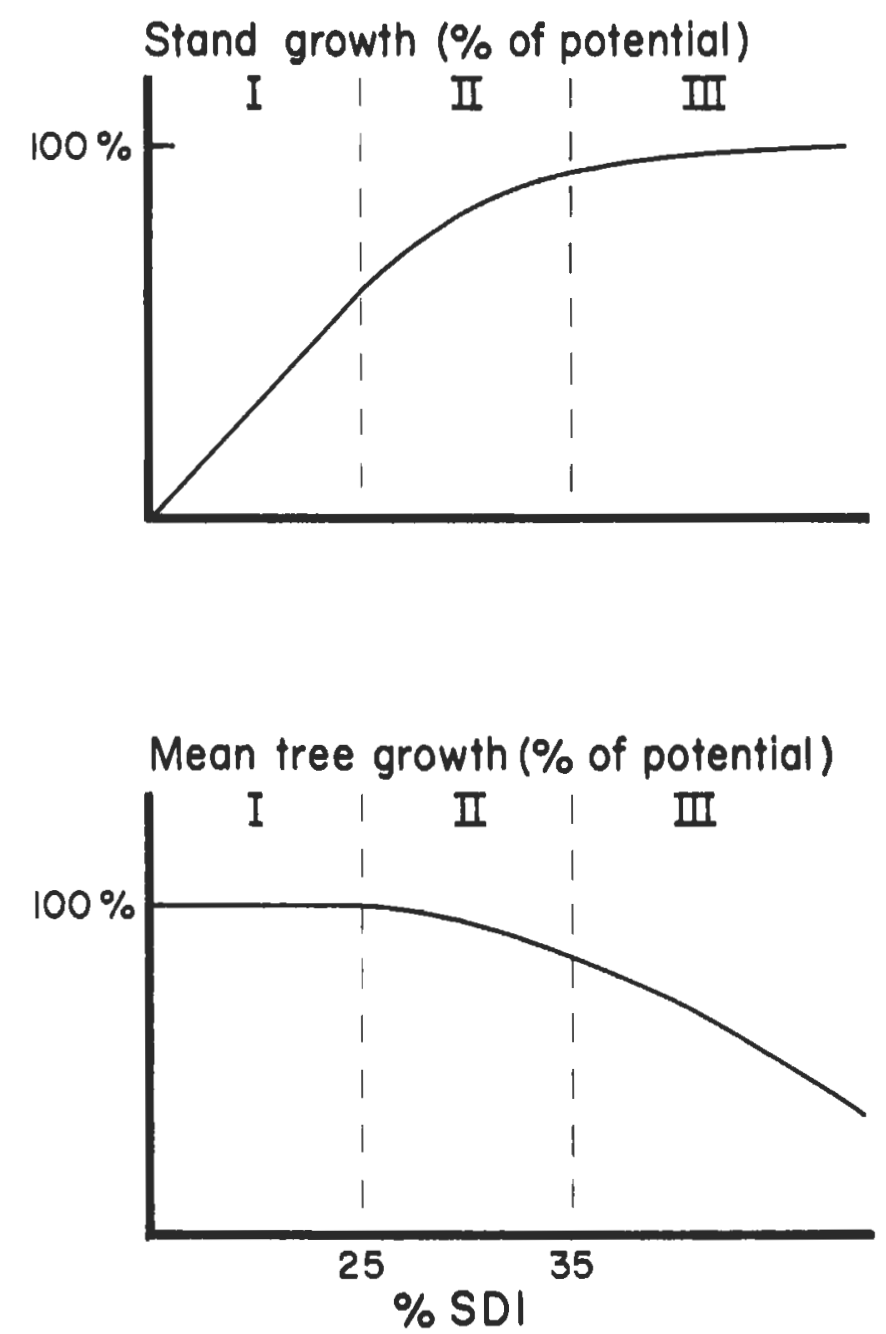

Figure 2. Current annual stand and individual tree growth as related to growing stock. \% SDI is the actual SDl expressed as a percent of the species maximum SDI. Potential growth is dependent on species, site quality and stand age. (after Langsaeter 1941).

The nature of the silvicultural trade-off between stand versus individual tree growth in a specific situation is a direct consequence of the management objectives. By way of a simple example, if the management objective were to maximize total volume production, without regard to individual tree size, upper and lower limits of growing stock would be chosen in order to maintain the stand with in Zone III (Figure 2) for most of the rotation. Alternatively, if the management objective were to maximize individual tree growth and size, without regard to volume production on an area basis, an appropriate strategy would be to maintain the stand within Zone 1.

SDI represents an effective index with which to translate growing stock objectives into density management prescriptions. The following examples illustrate possible criteria that might be used in arriving at appropriate upper and lower levels of growing stock.

An important criterion that might be used in arriving at a target upper level of growing stock is a minimum acceptable rate of individual average tree growth. If the level of growing stock in a stand is above the threshold for competitive interaction (i.e., transition between zones I and II, Figure 2), individual tree growth falls below the potential for open-grown trees of that species, site quality and age. Management constraints involving minimum merchantable tree sizes, value production and harvesting costs may dictate that levels of growing stock not be allowed to exceed a certain level. So called "minimum tending" or "sudden sawlog" regimes would involve using a relatively low $\mathrm{SD}$ as the upper limit to growing stock.

Another possible criterion in deciding on an appropriate upper limit is a minimum acceptable level of individual tree vigor. The vigor of trees in a stand is related to their ability to quickly respond to thinning (Walkup 1975) and their susceptibility to various pests (Keen 1936; Westveld 1954; Waring and Pitman 1980). A llve crown to total stem height ratio of at least $40 \%$ has been cited for a number conifers as representing a generally acceptable level of individual tree vigor (Danielet al. 1979). For several coniferous species, a live crown ratio of $40 \%$ seems to correspond with an SDI of about $50 \%$ of the maximum SD| for the species (Figure 3).

Live Crown $(\%)$

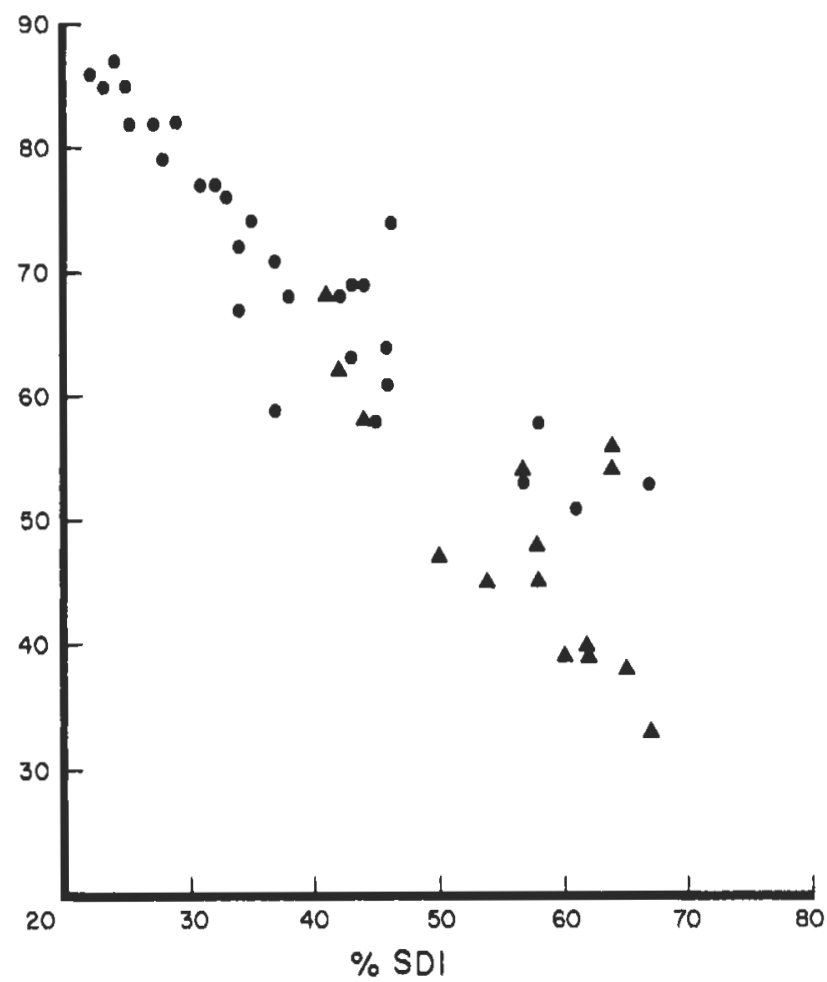

Flgure 3. Relation between average live crown ratio (lenath of live crown/total stem height) and \% SDI for stands of Douglasfir $(o)$ and lodgepole pine $(\delta)$

A more conservative upper limit to density is one that merely avoids self-thinning or suppression-related mortality. A SDI of less than or equal to $60 \%$ of the maximum SD| for the species 
would result in stands largely free from self-thinning (Wiley 1976; Drew and Flewelling 1977, 1979; Flewelling 1981 McCarter 1984). It would also, of course, result in trees substantially smaller than if the upper limit SDI were lower.

A decision concerning the lower limit to stand density

The level of growing stock after thinning affects the growth of both the stand and the individual trees (Figure 2). Setting of a lower limit to stand density involves answering the question, "How much of the potential volume production of the site am I willing to give up in return for increased individual tree growth and size?" If, for example, the answer is "very little", a suitable target lower limit might be approximately $35-40 \%$ of the maximum SDI for the species. Alternatively, a "sudden sawlog" regime might involve the use of substantially lower SDIs following thinning.

Objectives concerning the desired interval between thinning entries affect both upper and lower limits to stand density. The closer the upper and lower limits are to each other, the shorter the reentry period and, in general, the greater the percentage of the potential volume production of the site that will be captured.

To illustrate the process, two simple density management regimes will be developed for a hypothetical even-aged stand with approximately 2000 tpha. These trees are evenly spaced and currently average less than $5 \mathrm{~cm}$ DBH. The species involved has a maximum SDI of approximately 1700 (e.g. lodgepole pine). The objectives and the assumptions that are made, are simplistic; however, they serve to illustrate the process.

The first example ("high volume") assumes that a relatively high priority is to be placed on the maximization of volume production. To assure prompt response to thinning, an upper limit of 850 (i.e., about $50 \%$ of the SDI max) is chosen. A lower limit of 600 (i.e., about $35 \%$ of the SDImax) is chosen. This choice of upper and lower limits should result in reasonably full site utilization, vigorous crop trees, and prompt release following thinning. It is further assumed that a $\mathrm{DBH}_{\mathrm{q}}$ of at least $20 \mathrm{~cm}$ is necessary for a thinning entry to be considered commercial. A target of $40 \mathrm{~cm}$ is assumed for the end-ofrotation $\mathrm{DBH}_{\mathrm{q}}$.

Table 2 illustrates the resulting "high volume" density management regime. The three fairly light commercial thinnings called for are consistent with the objective of full site utilization and high volume production. The first commercial entry has been "set up" with a pre-commercial thinning (PCT) that reduced the level of growing stock to approximately 1,125 tpha. It is logical that the PCT should be done prior to the on-set of competive interaction to avoid unnecessary loss of growth by crop trees. In the current example, this would correspond to a DBHq of about $9.5 \mathrm{~cm}$ or less (i.e. 2000 toha and $\mathrm{SDI}=425$, or $25 \%$ of the $\left.S D I_{\max }\right)$.

Table 2. "High volume" density management regime.

\begin{tabular}{cccccc}
\hline ENTRY & \multicolumn{2}{c}{ SDI } & \multicolumn{2}{c}{ TPHA } & DBH $_{\mathbf{q}}(\mathbf{c m})$ \\
& Before & After & Before & After & \\
\hline PCT & & & 2000 & 1125 & 5.0 \\
1st CT & 850 & 600 & 11259 & 800 & $21.0^{f}$ \\
2nd CT & 850 & 600 & $800^{\circ}$ & 565 & $26.0^{\mathrm{d}}$ \\
3rd CT & 850 & 600 & $565^{\mathrm{C}}$ & 400 & $32.2^{\mathrm{b}}$ \\
Final & 850 & - & $400^{\mathrm{a}}$ & - & 40.0 \\
\hline
\end{tabular}

a Given end-of-rotation rarget $\mathrm{sol} S \mathrm{SD}=850 \mathrm{and} \mathrm{DBH}=40 \mathrm{~cm}$, calculate tpha using equation 2 Given after thimning $\mathrm{SOI}=600$ and 400 tpha. calculate DBH using equation 3 .

2 Given after thinning $\mathrm{SOH}=600$ and 400 toha. Calculate DBH using equation 3 .
$\mathrm{C}_{\mathrm{Given}} \mathrm{DBH}=32.2 \mathrm{~cm}$ and betore thimning $\mathrm{SOI}=850$ calculate betore thirning tpha using equation 2 .

$d_{G}$ Given atter thinning $S D r=600$ and 565 tona, calculate DBH using equation 3

e $G$ rven $D B H=260 \mathrm{~cm}$ and before thinning $S D \mid=850$. calculate before thinning tpha using equation 2 .

Given atter thirining $\mathrm{SOI}=600$ and 800 tha calculate DBH using equation 3

$9 \mathrm{G}$ iven $\mathrm{DBH}=21.0 \mathrm{~cm}$ and betore thinning $\mathrm{SOI}=850$. calculate before thimung lpha using equation 2
The second example represents a "sudden sawlog" or "minimum tending" regime (Table 3 ). This example assumes no commercial thinnings and a final $\mathrm{DBH}_{\mathrm{q}}$ of $35 \mathrm{~cm}$ in a relatively short rotation. To maintain reasonably fast individual tree growth rates, an upper limit SDI of 600 is chosen. This combination of end-of-rotation SDI and $\mathrm{DBH}_{\mathrm{q}}$ corresponds to 350 tpha. This will be "set-up" with a precommercial thinning (leaving about 350 tpha) prior to a SDI of 425 (i.e. before the $\mathrm{DBH}_{\mathrm{q}}$ is $9.5 \mathrm{~cm}$ ).

\begin{tabular}{|c|c|c|c|c|c|}
\hline \multirow[t]{2}{*}{ ENTRY } & \multicolumn{2}{|c|}{ SDI } & \multicolumn{2}{|c|}{ TPHA } & \multirow{2}{*}{$\mathrm{DBH}_{\mathrm{q}}(\mathrm{cm})$} \\
\hline & Before & After & Before & After & \\
\hline $\begin{array}{l}\text { PCT } \\
\text { Final }\end{array}$ & 600 & - & $\begin{array}{c}2000 \\
350 a\end{array}$ & $\begin{array}{c}350 \\
-\end{array}$ & $\begin{array}{r}5.0 \\
35.0\end{array}$ \\
\hline
\end{tabular}

$\mathrm{a}_{\mathrm{G}}$ ven end-of-rotation targets of $\mathrm{SDI}=600 \mathrm{and} \mathrm{DBH}=35.0 \mathrm{~cm}$. calculate $\mathrm{ph}$ a using equation

\section{Summary}

Stand density indices that are based on size-density relationships constitute a valuable tool in translating management objectives into practical density management regimes. Commonly, management objectives involve some form of compromise between the mutually exclusive goals of maximizing either stand or individual tree growth. SDI, which is independent of site quality and stand age, allows management objectives to be translated into specific target levels of growing stock. Reasonable generalizations concerning growthgrowing stock relationships for a particular species, coupled with a suitable stand density index, allow at least good first approximations of rational density management regimes.

\section{References}

Ando, T. 1968. Ecological studies on the stand density control in even-aged stands. Bull. Gov. For. Exp. Sin. Tokyo 210:1-153.

Curtis, R.O. 1970. Stand density measures: an interpretation. Forest Sci. 16: $403-414$

Curtis, R.O. 1971. A tree area power function and related stand density measures for Douglas-fir. Forest Sci. 17: 146-159.

Daniel, T.W., J.A. Helms and F.S. Baker. 1977. Principles of Silviculture (2nd ed.). McGraw-Hill, N.Y. 500 p.

Daniel, T.W. and H. Sterba. 1980. Zur ansprache der bestandesdichte. Allgemeine Forstzeitung 91: 155-157.

Davis, K.P. 1966. Forest Management: Regulation and Valuation (2nd ed.). McGraw-Hill, N.Y. 519 p.

Drew, J.T. and J.W. Flewelling. 1977. Some recent Japanese theories of yield-density relationships and their application to Monterey pine plantations. Forest Sci. 23: 517-534

Drew, J.T. and J.W. Flewelling. 1979. Stand density management: an alternative approach and its application to Douglas-fir plantations. Forest Sci. 25: 518-532.

Flewelling, J.W. 1981. A comparison of three stand density indices for predicting gross volume growth in plantations of loblolly pine. Disseration. Univ. Georgia, Athens, Georgia. 83 p.

Gorham, E. 1979. Shoot height, weight and stand crop in relation to density of monospecific plant stands. Nature 279: 148-150

Hutchings, M.J. and C.S.J. Budd. 1981. Plant competition and its course through time. BioScience 3: 640-645.

Keen, F.P. 1936. Relative susceptibility of Ponderosa pine to barkbeetle attack. J. For. 34: 919-927.

Langsaeter. A. 1941. Om tynning i enaldret gran-og furuskog. Meddel. f. d. Norske Skogforsoksvesen 8: 131-216

Long, J.N. and F.W. Smith. 1984. Relation between size and density in developing stands: a description and possible mechanism. For. Ecol. and Management 7: 191-206

McCarter, J.B. 1984. Density management of lodgepole pine. Thesis, Utah State Univ., Logan, Utah. $37 \mathrm{p}$

Reineke, L.H. 1933. Perfecting a stand density index for even-aged forests. J. Agric. Res. 46: 627-638. 
Walkup, R.H. 1975. Sense and cents of space in managing a young western hemlock forest. In Western Forestry and Conservation Assoc. Proc. 1975, p. 135-139.

Waring, R.H. and C.B. Pitman. 1980. A simple model of host resistance to bark bettle attack. Res. Note 165. For. Res. Lab. Oregon State Univ., Corvallis, Oregon. 2 p.

Westveld, M. 1954. A budworm vigor-resistance classification for spruce and balsam fir. J. For. 52: 11-24

White, J. 1980. Demographic tactors in populations of plants. in O.T Solbrig (editor) Demography and Evolution in Plant Populations. Blackwell, Oxford. P. 21-47.

Wiley, K.N. 1976. Site index and yield of western hemlock. In W.A. Atkinson and R.J. Zasoski (editors). Proc. Western Hemlock Management Conference, May 1976, Inst. For. Products. Univ. Washington, Seattle, WA, p. 228-235

Wilson, F.G. 1979. Thinning as an orderly discipline: a graphic spacing schedule for red pine. J. For. 77: 483-486

Yoda, K., T. Kira, H. Ogana and K. Hozumi. 1963. Self-thinning in overcrowded pure stands under cultivated and natural conditions. J. Biol. Osaka City Univ. 14:107-129.

\section{FOREST MANAGEMENT POSITION}

The Canadian Pulp and Paper Association, located in Montreal, has an opening for a graduate forester experienced in forest management.

The CPPA is a national association representing the interests of the pulp and paper industry across Canada.

Three of the Association's main activities are:

- to collect and compile industry statistics;

- to provide a forum for the exchange of technical information through the organization of technical committees, seminars and field trips ("technology transfer");

- to represent the industry on matters of policy.

Position title: Co-ordinator - Forest Management Group.

The Forest Management Group comprises 90 senior forest management professionals working for pulp and paper companies, universities and governments. The Group participates in: collection and compilation of forest management statistics; technical committees; technical seminars and conferences; and field trips in Canada and overseas.

The job offers an exceptional opportunity to become familiar with practical, technical and policy aspects of forest management across Canada. Candidates for the position should have a university degree in forestry, 10-15 years experience in forest management with industry or government, and good written and oral communication skills.

A good command of English is essential, and working knowledge of French would be a strong asset.

In addition to coordinating the activities of the Forest Management Group, the position involves participation in developing and communicating resource policies on behalf of the industry, and a strong technical and policy role in a forest protection committee. This committee deals with all aspects of forest protection, including acid rain, pesticides, and forest fire.

The position is a full time career position with an attractive package of benefits. It will interest forest management professionals who wish to broaden their knowledge of technical and policy aspects of forest management in Canada, and who are now earning $\$ 35-40 \mathrm{~K}$. The position is available now. All applications will be treated with strict confidence.

Please submit your letters of applicatio and resumés marked "PERSONAL" to:

D.C. MacGregor

Manager, Woodlands Section

Canadian Pulp and Paper Association

Sun Life Building, 23rd Floor

1155 Metcalfe Street

Montreal, Quebec

$\mathrm{H} 3 \mathrm{~B} 2 \mathrm{X9}$ 